\title{
PHASE FIELD MODELING OF CYCLIC FATIGUE CRACK GROWTH UNDER MIXED MODE LOADING
}

\author{
Christoph Schreiber*, Charlotte Kuhn, Ralf Müller \\ Institute of Applied Mechanics, Technische Universität Kaiserslautern, Germany \\ *Corresponding author: schreibc@rhrk.uni-kl.de
}

\begin{abstract}
For the numerical handling of nucleation and extension of cracks within different materials, phase field modeling of fracture was shown to be a very beneficial technique in the past decade. Within numerous studies the framework was successfully applied even to complex crack problems. However, a phenomenon, which has not been much in the focus of research in terms of phase field modeling, is cyclic fatigue crack growth. Within technical developments this phenomenon is crucial as it has been found to be the source of several devastating accidents in the past. Within this work we introduce a phase field model capable of capturing fatigue crack growth under unidirectional as well as mixed mode loading. The driving force of the fatigue mechanism is controlled by cyclic damage evaluated from Miner's rule, a very famous and robust phenomenological law within fatigue simulations. Among the prediction of realistic crack growth curves, the accuracy of the model is verified by comparison with analytic results regarding the crack growth direction.
\end{abstract}

Key words: Phase field, Fatigue crack, Fracture, Finite elements

\section{INTRODUCTION}

The motivation for research within the field of cyclic mechanical fatigue is basically a large number of failures of components in machines or structures, like airplanes, trains, bridges, turbines, pressure vessels and others, leading to catastrophic accidents. Fatigue can be defined as damage or failure of a material caused by cyclic loading where maximum load values for fatigue failure can be far below quasi static design limits. The reasons for this, as it is outlined in several textbooks like e.g. (Dowling, 2013; Schijve, 2009; Haibach, 2006), is cyclic slip occurring below global stress levels within grains of proper orientation with respect to the loading. The material becomes more and more disrupted as additional slip systems get involved due to ongoing cycling until a micro crack is generated. Within fatigue lifetime estimation, it is differentiated between the phase of crack nucleation and the phase of macro crack growth until the final overload fracture. The first phase is mainly described by so-called Wöhler curves, which are also called S-N curves. This law has an experimental basis and assigns a certain number of bearable load cycles to a certain load amplitude. The second phase of the fatigue live i.e. the macro crack growth phase is described by a power law for the crack growth rates depending on the particular cyclic stress intensity factor range $\Delta K$, namely Paris' law (Paris \& Erdogan, 1963). This law is incorporated within the probably most famous conventional numerical fatigue crack tool NASGRO (Forman et al., 2005).

Compared to conventional crack simulation approaches, within phase field fracture models it is unnecessary to delete or disconnect elements and also no remeshing is required since one discretization is sufficient to deal with cracks simply via an additional

${ }^{1}$ The paper presented during YIC 2019, ECCOMAS Young Investigators Conference held in Kraków, Poland on September 1-6, 2019 
degree of freedom indicating which phase (intact material or crack) is present at a certain location. This framework was so far applied to quasi static brittle fracture (Kuhn \& Müller, 2010; Borden et al., 2014; Miehe et al., 2010), anisotropic fracture (Teichtmeister et al., 2017; Schreiber et al., 2017; Hakim \& Karma, 2009), ductile fracture (Kuhn et al., 2016; Borden et al., 2016) as well as to dynamic fracture (Schlüter et al., 2014). Phase field modeling of fatigue fracture was so far handled by Alessi et al., (2017) and by Seiler et al., (2018). Within the models from these studies the fracture toughness of the material is decreased once an accumulated strain measure increases. In contrast, we incorporate the fatigue mechanism occurring in a material by means of an additional driving force contribution caused by cyclically accumulated deformation work. The model is an enhancement of the model for brittle fracture (Kuhn \& Müller, 2010). The enhancement accounts for fatigue damage accumulation as consequence of a permanent sequence of loading and unloading.

\section{MODEL DESCRIPTION}

\subsection{Regularized phase field model for brittle fracture}

The basic characteristic of a phase field fracture model is the introduction of an additional degree of freedom in order to represent cracks. This additional field parameter retains 1 as long as the material can be refereed as intact. Once a crack nucleates or extends, the field parameter will decrease to 0 , where the transition from 1 to 0 is continuous in space and time. Within the presented model the field parameter is designated as $s(\boldsymbol{x}, t)$ and as indicated above its value is limited to $[0,1]$. The basic model for our investigation follows Kuhn and Müller (2010), which makes use of a regularized formulation of the variational model for brittle fracture presented by Bourdin et al. (2000). Therefore, the total energy within a loaded sample:

$$
\begin{aligned}
E(\varepsilon, s, \nabla s) & =\int_{\Omega} \psi(\varepsilon, s, \nabla s) \mathrm{d} V \\
& =\int_{\Omega}(g(s)+\eta) W(\varepsilon)+\Gamma(s, \nabla s) \mathrm{d} V
\end{aligned}
$$

has to be minimized. In equation (1), $W$ is the elastic strain energy density, the function $g$ is a degradation function accounting for stiffness decrease in case of cracking and the parameter $\eta$ must be chosen such that $0<\eta \ll 1$, so a residual stiffness $\eta \mathbb{C}$ is ensured for areas with $s=0$. This is important to enable a stable solution procedure. The crack energy density $\Gamma$ is defined as:

$$
\Gamma(s, \nabla s)=G_{c}\left[\frac{\left(1-s^{2}\right)}{4 \epsilon}+\epsilon|\nabla s|^{2}\right]
$$

where the parameter $G_{c}$ is the critical energy release rate and $\epsilon$ is the length scale, which controls the width of the transition zone between undamaged and fractured material. Equation (2) is a regularization of Griffith's surface energy and accordingly the minimization of equation (1) is also in the sense of Griffith's theory, which states that a crack propagates once the release of strain energy is balanced by the amount of required surface energy. In case of a hyper elastic material the stresses can be derived by:

$\boldsymbol{\sigma}=\frac{\partial \psi}{\partial \boldsymbol{\varepsilon}}=(g(s)+\eta) \mathbb{C} \boldsymbol{\varepsilon}$,

where $\varepsilon$ is the linearized strain tensor and $\mathbb{C}$ is the material tensor. The degradation function has to fulfil $g(0)=0, g(1)=1$ and also $g^{\prime}(0)=0$. These restrictions are fulfilled by $g(s)=s^{2}$ (see e.g. Kuhn et al. 2015), which will be set as degradation function within this work. A generalized Ginzburg-Landau equation (Gurtin, 1996) is applied to find the time evolution of the phase field $s$ by:

$$
\begin{aligned}
\dot{s} & =-M\left\{\frac{\partial \psi}{\partial s}-\nabla \cdot\left(\frac{\partial \psi}{\partial \nabla s}\right)\right\} \\
& =\frac{-M}{2}\left\{g^{\prime}(s) \boldsymbol{\varepsilon}^{T} \mathbb{C} \boldsymbol{\varepsilon}-G_{c}\left(4 \epsilon \Delta s+\frac{1-s}{\epsilon}\right)\right\}
\end{aligned}
$$

In equation (4) the Voigt notation for symmetric tensors is applied to the stiffness tensor $\mathbb{C}$ and to the linearized strain tensor $\varepsilon$. The mobility parameter $M$ can be considered as viscous regularization value to approach quasi static conditions by the limit $M \rightarrow \infty$.

\subsection{Phase filed model for cyclic fatigue}

Suppose the phase field model for quasi static fracture (Kuhn \& Müller, 2010) is used within a simulation where a monotonous increasing load is applied to a sample. In this case, cracks will definitely be included in the solution, as at a certain point it will be energetically more favorable to decrease $s$ than to allow for more strain energy. However, the problem for an application for cyclic loading is, that the load amplitudes within the range where the fatigue phenomenon occurs are small to very small. Without a 
modification, a crack will never occur in the solution, as this would simply be too costly from an energetic viewpoint, even if an infinite number of load cycles is simulated. Therefore, an enhanced version of the regularized formulation of the total energy was introduced in (Schreiber et al. 2019) as:

$$
\begin{aligned}
E^{f} & \left(\varepsilon, s, \nabla s, D_{f}\right)=E+E^{a c} \\
& =\int_{\Omega}(g(s)+\eta) W(\varepsilon)+\Gamma \mathrm{d} V+\int_{\Omega} h(s) P\left(D_{f}\right) \mathrm{d} V
\end{aligned}
$$

with the additional energy density contribution $P$, which is intended to account for additional driving forces caused by the phenomenon of cyclic fatigue. The function $h(s)$ is another degradation function to reduce the energy from $P$ once a crack evolves. The energy $E^{a c}$ has to increase rapidly once a critical value of fatigue damage is reached at a certain location as otherwise the cracks would extend lateral instead of growing as a line. This is ensured by the function:

$$
P\left(D_{f}\right)=q\left\langle D_{f}-D_{f c}\right\rangle^{b}
$$

where $D_{f}$ is the local fatigue damage, $D_{f c}$ is a critical threshold value. The $\langle\cdot\rangle^{n}$ are Macauley brackets with the definition: $\langle\cdot\rangle^{n}=0$ for $(\cdot) \leqslant 0$ and $\langle\cdot\rangle^{n}=(\cdot)^{n}$ for $(\cdot)$ $>0$. The parameters $q$ and $b$ must be chosen in order to ensure a rapid decrease once $D_{f}$ exceeds $D_{f c}$. The crucial task is now to define a proper estimate for $D_{f}$ or the increment $d D_{f}$ respectively. In the literature one can find different approaches, e.g. those presented from Miner (1945) or Chaboche and Lesne (1988). Generally, every approach could be incorporated in the model presented here. However, the challenge is of course to obtain the best trade of between complexity, costs and quality of the prediction. Therefore, within this work the law from Miner (1949) will be used due to its simplicity and robustness. According to this law the damage increment can be evaluated with the linear relation:

$$
d D_{f}=\frac{1}{N_{F i}} d N
$$

where $N_{F i}$ is the number of bearable load cycles to failure for a certain load amplitude. This number can be obtained by $S-N$ curves, which are empirical laws obtained from cyclic tensile test relating stress amplitude to $N_{F i}$. Using these equations, the total internal energy of a sample subjected to cyclic loading, which may also contain fatigue cracks is found by:

$$
\begin{aligned}
E^{f} & =\int_{\Omega}[(g(s)+\eta) W(\varepsilon)+\Gamma \\
& \left.+h(s) q\left\langle D_{0}+\frac{d N}{n^{D}}\left(\frac{\sigma_{A}}{A_{D}}\right)^{k}-D_{c}\right)^{b}\right] \mathrm{d} V
\end{aligned}
$$

The incorporated equations represent materials, which reveal a liner relation between load amplitude and cycles to failure using logarithmic scales, and accordingly in the first place the presented model addresses isotropic metallic materials. However, generally other relations for the fatigue damage evolution may be incorporated to handle a larger variety of materials. The significant driving force in equation (8) is $\sigma_{A}$, which is an amplitude value of the applied load cycles. In (Schreiber et al. 2019) simply the normal stress perpendicular to the tensile load was used for this value. This is sufficient for straight cracks occurring under unidirectional loading, but for mixed mode loading normal stress is not appropriate as it will not predict the correct crack path. Erdogan and Sih (1963) proposed the Maximum Tangential Stress (MTS) criterion for mixed mode loading, which basically states that a crack will extend perpendicular to the direction of the greatest tension around the crack tip. It can be shown (see e.g. Kuna (2008)) that this MTS is a principal stress. Accordingly, to enable the phase field model to handle mixed mode loading the first principal stress has to be incorporated as the amplitude value $\sigma_{A}$ and in a two dimensional setting:

$\sigma_{A}=\frac{\sigma_{x}+\sigma_{y}}{2}+\sqrt{\frac{\left(\sigma_{x}-\sigma_{y}\right)^{2}}{2}+\tau_{x y}^{2}}$

Applying these modifications, the stresses become:

$$
\begin{aligned}
\boldsymbol{\sigma}= & (g(s)+\eta) \mathbb{C} \boldsymbol{\varepsilon} \\
& +h(s) q b\left\langle D_{f}-D_{f c}\right\rangle^{(b-1)} \frac{d N k}{n^{D} A_{D}^{k}} \sigma_{A}^{(k-1)} \frac{\partial \sigma_{A}}{\partial \boldsymbol{\varepsilon}}
\end{aligned}
$$

with the derivative:

$$
\begin{aligned}
& \frac{\partial \sigma_{A}}{\partial \boldsymbol{\varepsilon}}=\mathbb{C} \mathbf{1}_{+} \\
& +\left[\left(\mathbf{1}_{-}^{T} \mathbb{C} \boldsymbol{\varepsilon}\right) \mathbb{C} \mathbf{1}_{-}+\left(\mathbf{1}_{\tau}^{T} \mathbb{C} \boldsymbol{\varepsilon}\right) \mathbb{C} \mathbf{1}_{\tau}\right]\left[\left(\mathbf{1}_{-}^{T} \mathbb{C} \boldsymbol{\varepsilon}\right)^{2}+\left(\mathbf{1}_{\tau}^{T} \mathbb{C} \boldsymbol{\varepsilon}\right)^{2}\right]^{-1 / 2}
\end{aligned}
$$

In equation (11) the Voigt notation for symmetric tensors is applied to $\mathbb{C}$ and $\boldsymbol{\varepsilon}$. Further, the operators $\mathbf{1}_{+}=[1 / 2,1 / 2,0]^{T}, \mathbf{1}_{-}=[1 / 2-1 / 2,0]^{T}$ and $\mathbf{1}_{\tau}=[0,0,1]^{T}$ are introduced. According to this, the stresses introduced in equation (10) consist of two contributions. The first term accounts for static stresses and the second term 
considers a contribution coming from accumulated micro stresses caused by the fatigue mechanism.

\subsection{Simulation scheme}

Within fatigue tests a very high number of load cycles generally has to be applied before crack nucleation and growth can be observed. To explicitly simulate every cycle would cause enormously high computational effort. Therefore, load cycles must be collected in blocks and the effect in terms of damage may then be integrated within the simulation scheme. A procedure called cycle jump was presented by Fish and $\mathrm{Yu}$ (2002). According to this scheme basically the damage caused by a certain number of load cycles is approximated and applied within one simulation step. This scheme is used within this work and accordingly the damage of the current simulation step $D_{i}$ is:

$$
D_{i}=D_{i-1}+d D_{f}\left(\Delta N_{i}\right)
$$

where $D_{i-1}$ is the stored damage from the previous step. The block size of $\Delta N_{i}$ is chosen adaptively to ensure a reliable convergence behaviour.

Using chain rule differentiation, the phase field evolution equation (4) can be transferred to the cycle domain and is then reformulated in terms of cycles as:

$$
\frac{d s}{d N}=-m\left\{g^{\prime}(s) \frac{1}{2} \varepsilon^{T} \mathbb{C} \boldsymbol{\varepsilon}+h^{\prime}(s) P\left(D_{f}\right)-G_{c}\left(2 \epsilon \Delta s-\frac{s-1}{2 \epsilon}\right)\right\}
$$

with $m$ now denoted as the mobility in the cycle domain.

Cyclic loads are often applied under high frequencies and energy dissipation may therefore not be neglected within a model considered as generally valid. As within this work, basic features of the enhanced model are investigated a constant value for this kinetic coefficient of $m=1 \frac{L}{G_{C} T}$ with length parameter

$L$ time scale $T$ and critical energy release rate, was chosen to ensure equal conditions throughout all performed simulations. However, to develop an even more general model the frequency effects must be considered within further studies.

\section{NUMERICAL EXAMPLES}

In this section the performed simulations will be explained in detail and results are discussed. The model was discretized and the nonlinear system of equations was solved within an implicit finite element scheme, where a user element routine of a 4-node quadrilateral element was implemented in FEAP 8.4. The finite element meshes were refined at areas expected for cracking to an edge length of approximately $0.3 \mathrm{~mm}$ to ensure a proper ratio of the element size and the length scale $\epsilon$. A to large length scale would lead to an overestimation of the crack energy, which may affect the result in terms of crack extension direction. The material properties used for the simulations are shown in table 1.

Table 1. Material parameters used for phase field simulations.

\begin{tabular}{|c|c|}
\hline Young's modulus $E$ & $210 \mathrm{GPa}$ \\
\hline Poisson's ratio $v$ & 0.3 \\
\hline Critical energy release rate $G_{C}$ & $2.3 \times 10^{3} \mathrm{~J} / \mathrm{m}$ \\
\hline Fatigue limit $A_{D}$ & $195 \mathrm{MPa}$ \\
\hline Fatigue life exponent $k$ & 5 \\
\hline Critical cycle number $n^{D}$ & $0.9 \times 10^{6}$ \\
\hline Length scale $\epsilon$ & $1.6 \times 10^{-4} \mathrm{~m}$ \\
\hline Residual stiffness parameter $\eta$ & $10^{-5}$ \\
\hline
\end{tabular}

\subsection{Mode-I loading of CT-specimens}

To investigate the general behavior of the derived phase field model, simulations were performed using the geometry of so-called compact tension (CT)specimens (see figure 1a), as these are also considered within experimental test set-ups for material characterization. This specimen was discretized with 3650 nodes and 2984 elements. All performed simulations within this subsection were force controlled. In order to approximate the cyclic loading with constant amplitudes in the phase field simulations a ramp function was used (see figure 1b).

As explained above, each simulation step represents a certain number of load cycles (cycle jump). The results of this simulation are shown by means of contour plots of the phase field variable $s$. These plots of the sections from the CT-specimen are illustrated in figure 2. After a certain number of simulated load cycles a crack nucleates at the notch root of the specimen, which can be observed by a drop of the phase field to zero . Furthermore, the crack grows in horizontal direction as consequence of ongoing cycling. Figure 3 shows results from three simulations in which different load sequences were applied. Within one sequence the high load cycles are applied first and those with lower amplitudes at last. For another sequence, the load sequence is inverted, such that at first the lower load cycles are applied. 

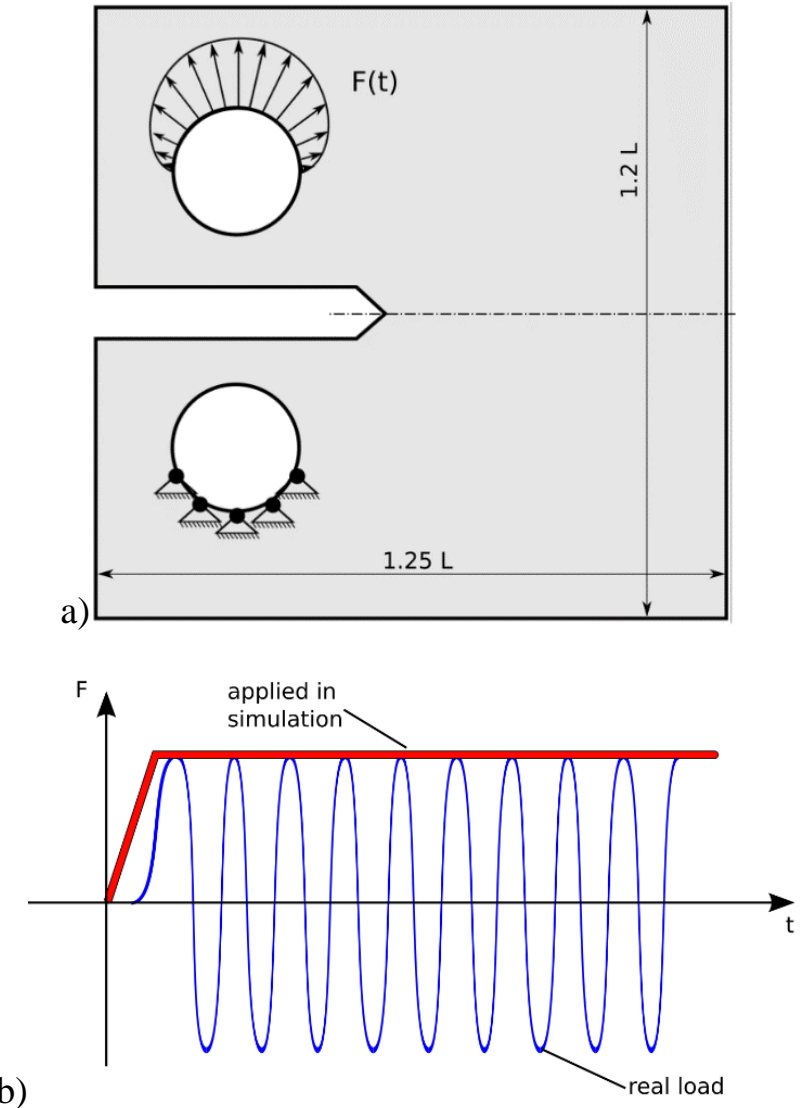

b)

Fig. 1. Set-up for simulations of mode-I test with CT-specimen: a) geometry, b) illustration of load sequences.

Generally, a very interesting observation is that the course of crack length versus the number of cycles is obviously non-linear. Therefore, the simulations are generally in line with fatigue experiments (see e.g. Dowling (2013)). In the previous section is was outlined that the Miner law which is utilized within the presented model for accumulation of damage is a linear law and it can therefore not account for sequence effects. However, comparing the crack growth curves for the different load sequences, one can observe that for the overall fatigue crack problem the sequence plays a roll and these effects on the crack propagation are covered in the simulations.

\subsection{Mode-II loading}

To verify the capability of the presented phase field model regarding the prediction of fatigue crack growth under mixed mode loading, the load case depicted in figure 4a was set up. A displacement load in horizontal direction was applied on the upper part of the pre-cracked specimen (discretized by approximately 10,000 elements), while the lower part was restrained. Accordingly, a plane shear loading was approximated at the crack tip. Applying polar coordinates, the analytic solution of the normal stress $\sigma_{\varphi}$ and the shear stress $\sigma_{r \varphi}$ is shown in e.g. Kuna (2008). This solution is illustrated in figure $4 \mathrm{~b}$. Considering this diagram one can see, that the maximum of the tangential stress $\sigma_{\varphi}$ occurs at about $-70.5^{\circ}$.
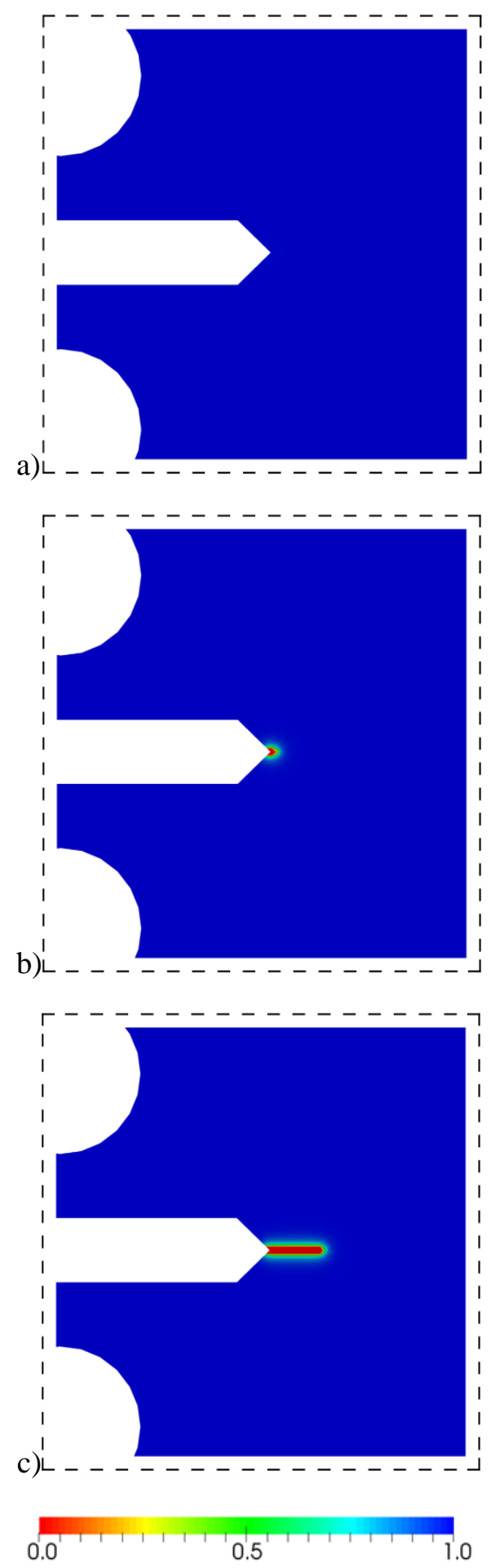

Fig. 2. Contour plots of CT-specimens after 0 cycles (a), 41000 cycles (b) and 90000 cycles (c). 


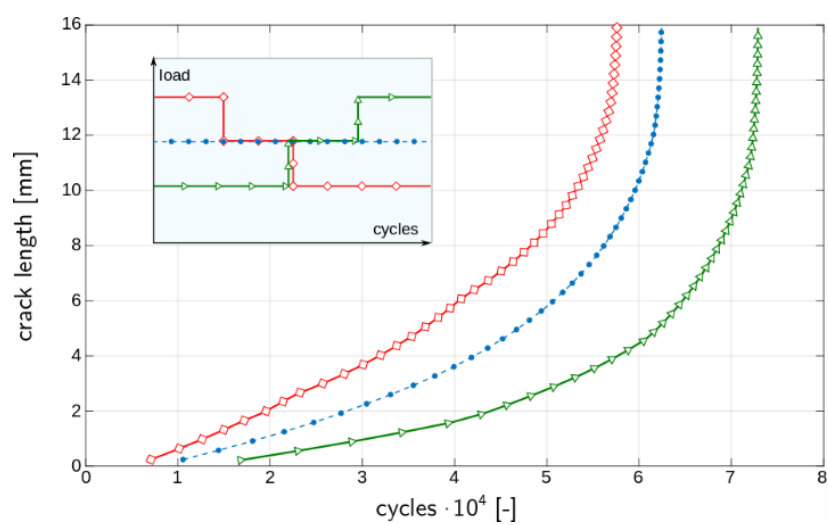

Fig. 3. Crack length with respect to number of applied load cycles for simuluatons with different load sequences.

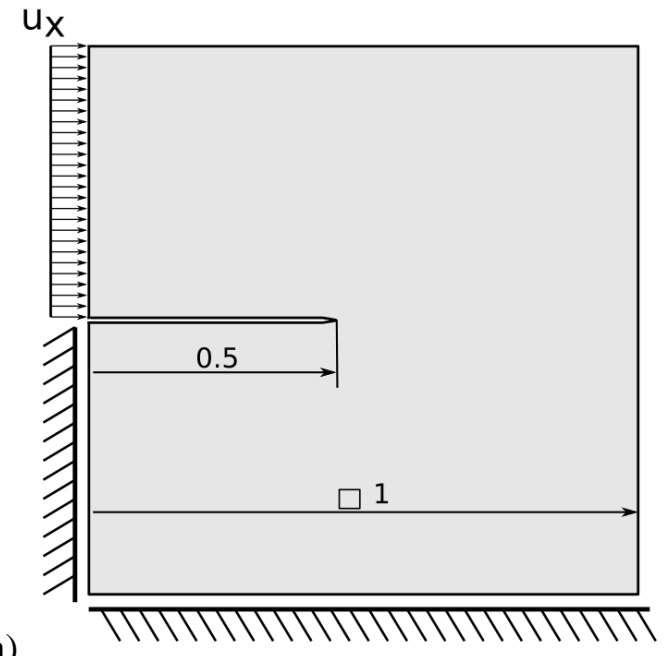

a)

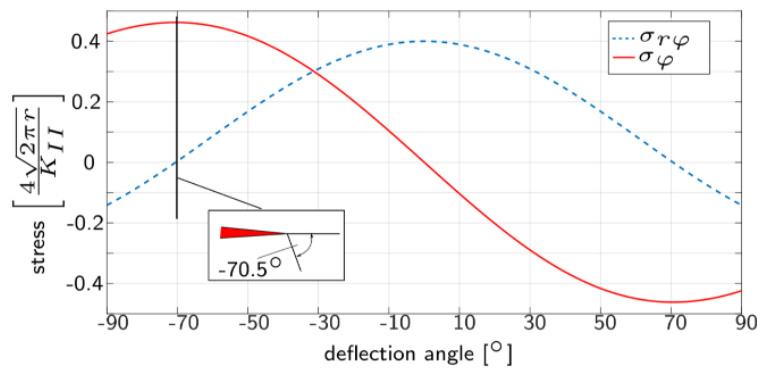

Fig. 4. a) Test set-up for simulation of mode-II load case, b) illustration of stress componets near the crack tip for a plane shear loading.

The results of the described mode-II simulation are shown in figure 5. The three contour plots of the phase field variable $s$ clearly indicate that the crack grows in the direction predicted by the analytic reference solution. In case of a quasi static simulation a second crack would evolve towards the $+70.5^{\circ}$ direction, since the basic phase field model for brittle fracture does not differentiate between tension or pressure. In the enhanced model for fatigue crack growth the tension compression differentiation is implicitly given by the incorporation of the $\mathrm{S}-\mathrm{N}$ line as this does not take load cycles into account, which are below a certain threshold (fatigue limit).

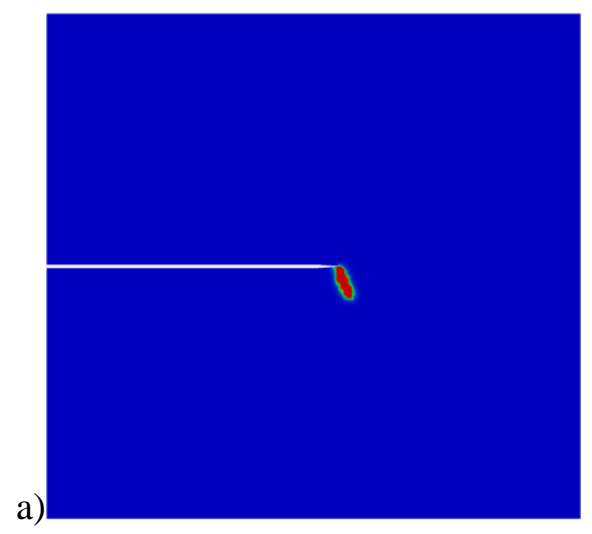

b)

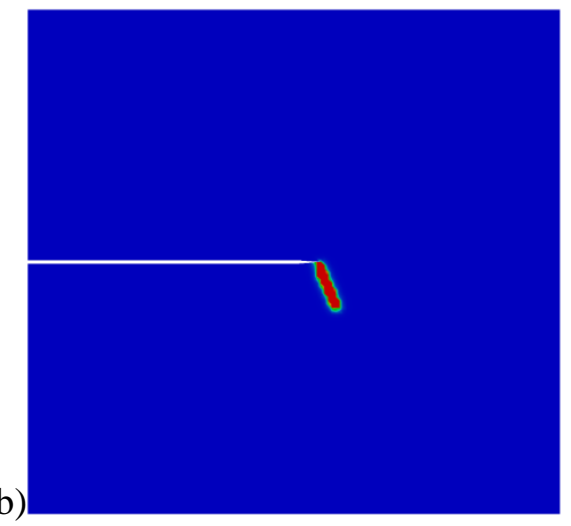

c)

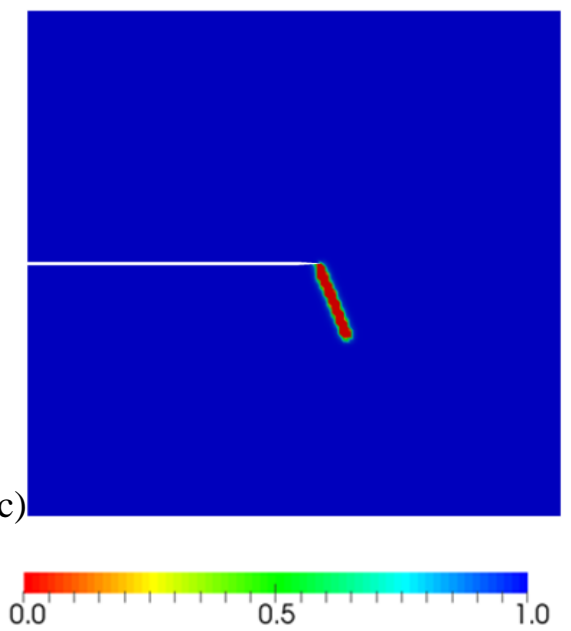

Fig. 5. Contour plots of the phase field variable s for 195,900 load cycles (a), 591,670 load cycles (b) and 881,400 load cycles (c).

\section{CONCLUSIONS}

In this work a phase field model for brittle fracture was enhanced, such that crack nucleation and extension due to cyclic mechanical fatigue is also included in the formulation. By means of different finite element simulations we showed that the presented model is able to adequately simulate mixed mode 
loading for fatigue crack growth estimations. Nevertheless, there is potential for further improvements and extensions of the model. For instance, important effects like strain rate, temperature, load ratio and mean stress must be included in the framework to deliver a more general tool.

\section{ACKNOWLEDGMENTS}

This research was funded by the Deutsche Forschungsgemeinschaft (DFG, German Research Foundation) - 252408385 - IRTG 2057.

\section{REFERENCES}

Alessi, R., Vidoli, S., DeLorenzis, L., 2017, A phenomenological approach to fatigue with a variational phase field model: The one-dimensional case, Engineering Fracture Mechanics, 190, 53-73.

Borden, M.J., Hughes, T.J.R., Landis, C.M., Verhoosel, C.V., 2014, A higher-order phase-field model for brittle fracture: Formulation and analysis within the isogeometric analysis framework, Computer Methods in Applied Mechanics and Engineering, 273, 100-118.

Borden, M.J., Hughes, T.J.R., Landis, C.M., Anvari, A., 2016, A phase-field formulation for fracture in ductile materials: Finite deformation balance law derivation, plastic degradation, and stress triaxiality effects, Computational Methods in Applied Mechanics and Engineering, 312, 130-166.

Bourdin, B., Francfort, G.A., Marigio, J.J., 2000, Numerical experiments in revisited brittle fracture, Journal of the Mechanics and Physics of Solids, 48, 797-826.

Chaboche, J.L., Lesne, P.M., 1988, A non-linear continuous fatigue damage model, Fatigue Fracture of Engineering Materials and Structures, 11, 1-17.

Dowling, N.E., 2013, Mechanical Behavior of Materials: Engineering Methods for Deformation, Fracture, and Fatigue, 4th edn, Person.

Erdogan, F., Sih, G.C., 1963, On the crack extension in plates under plane loading and transverse shear, J. Basic Eng., 85(4), 519-525.

Fish, J., Yu, Q., 2002, Computational mechanics of fatigue and life prediction composite materials and structures, Computer Methods in Applied Mechanics and Engineering, 191, 4827-4849.

Forman, R.G., Shivakumar, V., Cardinal, J.W., Williams, L.C., McKeighan, P.C., 2005, Fatigue crack growth database for damage tolerance analysis, National Technical Information Service, 126.

Gurtin, M.E., 1996, Generalized ginzburg-landau and cahn-hilliard equations based on a microforce balance, Physica $D$., 92, 178-192.

Haibach, E., 2006, Betriebsfestigkeit-Verfahren und Daten zur Bauteilberechnung, 3rd edn., Springer, Heidelberg,

Hakim, V., Karma, A., 2009, Laws of crack motion and phasefield models of fracture, Journal of the Mechanics and Physics of Solids, 57 (2), 342-368.

Kuhn, C., Müller, R., 2010, A continuum phase field model for fracture, Engineering Fracture Mechanics, 77, 3625-3634.
Kuhn, C., Noll, T., Müller, R., 2016, On phase field modeling of ductile fracture, GAMM Mitteilungen, 39, 35-54.

Kuhn, C., Schlüter, A., Müller, R., 2015, On degradation functions in phase field fracture models, Computational Materials Science, 108, 374-384.

Kuna, M. 2008, Numerische Beanspruchungsanalyse von Rissen, 1 st ed., Vieweg Teubner, Wiesbaden.

Miehe, C., Welschinger, F., Hofacker, M., 2010, Thermodynamically consistent phase-field models of fracture: Variational principles and multi-field fe implementations, International Journal for Numerical Methods in Engineering, 83 (10), 1273-1311.

Miner, M.A., 1945, Cumulative damage in fatigue, Journal of Applied Mechanics, 12, A159-A164.

Paris, P., Erdogan, F., 1963, A critical analysis of crack propagation laws, Journal of Basic Engineering, 85, 528-539.

Schijve, J., 2009, Fatigue of Structures and Materials, 2nd edn., Springer.

Schlüter, A., Willenbücher, A., Kuhn, C., Müller, R., 2014, Phase field approximation of dynamic brittle fracture, Computational Mechanics, 54, 1141-1161.

Schreiber, C., Kuhn, C., Müller, R., 2019, On phase field modeling in the context of cyclic mechanical fatigue, Proc. Appl. Math. Mech., 19 (1), doi: org/10.1002/pamm.201900104.

Schreiber, C., Kuhn, C., Müller, R., 2017, A phase field model for materials with anisotropic fracture resistance, Proceedings of the 7th GACM Colloquium, Stuttgart, 330-334.

Seiler, M., Hantschke, P., Brosius, A., Kästner, M., 2018, A numerically efficient phase-field model for fatigue fracture 1d analysis, Proc. Appl. Math. Mech., 18 (1), doi: 10.1002/pamm.201800207.

Teichtmeister, S., Kienle, D., Aldakheel, F., Keip, M. 2017, Phase field modeling of fracture in anisotropic brittle solids, International Journal of Non-Linear Mechanics, 97, 1-21.

\section{MODEL POLA FAZ DLA WZROSTU PEKNIECIA W CYKLICZNYM TEŚCIE ZMECZENIOWYM W WARUNKACH ZLOŻONYCH OBCIĄŻEŃ}

\section{Streszczenie}

W pracy wykazano, że w ostatnim dziesięcioleciu model pola faz okazał się efektywnym narzędziem do opisu zarodkowania i wzrostu pęknięć w różnych materiałach. Wielu badaczy skutecznie zastosowało ten model nawet do złożonych warunków obciążenia. Z drugiej strony problem wzrostu pęknięć w warunkach cyklicznych obciążeń zmęczeniowych nie był dotąd dogłębnie analizowany. To zjawisko było przyczyną wielu katastrof w przeszłości i stąd zasługuje na szczególną uwagę. W niniejszej pracy przedstawiono model pola faz pozwalający na opis wzrostu pęknięcia zarówno przy jednoosiowym jak i złożonym charakterze obciążeń. Siła pędna mechanizmu pękania jest kontrolowana przez cykliczne zniszczenie wyznaczane $\mathrm{z}$ reguły Minera, która jest znanym i skutecznym prawem stosowanych w modelowaniu pękania. Poza przewidywaniem realiztycznych krzywych pękania, przeprowadzono weryfikację modelu poprzez porównanie $z$ wynikami analitycznymi dla przewidywania kierunku wzrostu pęknięcia.

Received: September 30, 2019. Received in a revised form: November 30, 2019. Accepted: December 2, 2019. 